\title{
Understanding the Development of an Alumni Community: Conclusions based on a Conducted Survey. Ways to Support Alumni's Employability and Foster Entrepreneurship
}

\author{
Ioan-Radu PETRARIU ${ }^{\star}$
}

\begin{tabular}{l}
\hline \multicolumn{1}{c}{ A R T I C L E I N F O } \\
\hline Article history: \\
Accepted December 2019 \\
Available online December 2019 \\
\hline JEL Classification \\
A23, C83, D71, I24, L31 \\
Keywords: \\
Alumni, Association, Management, \\
Graduates, Research, Community, \\
Entrepreneurship, Employability
\end{tabular}

\begin{abstract}
A B S T R A C T
The Bucharest University of Economic Studies Alumni Association "ALUMNI ASE" challenged the graduates to take part in a research, in order to express their point of view on how the Association should be managed. The alumni showed their perception on how the Alumni Association might look in 2022, which is their potential role, what would motivate them to become active in the association and which benefits they are expecting to receive. Their suggestions describe an association with a wide range of activities, both formal and nonformal. Networking, transparency and more effective communication are among their priorities. Strengthening the link with the business environment is of great importance, as well as their participation in debates and conferences on current topics of interest. The "ALUMNI ASE" Association has all the premises for becoming a think-tank in the economic-financial sector, a space of interaction between stakeholders, a successful mix of qualitative human capital and material resources.
\end{abstract}

(C) 2019 EAI. All rights reserved.

\section{Introduction}

As Johnson (2015) states, alumni organizations are perceived as a "bonding tool" between alumni and the university organizing projects and facilitating communication. This kind of association is focused on providing different information regarding the activity of the alma mater, organising various alumni socialising and networking opportunities, offering career events, services and job offers, facilitating for the ones interested connections with authorities and decision-makers and also supporting university's fundraising policies. The association's work has a direct impact on the institution's awareness and brand and it has been proven that it also has an important role in the process of university developing.

This paper is based on the research conducted by the Bucharest University of Economic Studies Alumni Association "ALUMNI ASE" (hereinafter referred to as "the Association") between June 2018 and August 2018. The questionnaire was applied on a scale of 311 graduates of the Bucharest University of Economic Studies (hereinafter referred to as "ASE Bucharest"). The questionnaire was shared online both indirectly through social networks (e.g. Facebook, LinkedIn) and directly to the graduates via e-mail. For the realistic identification of their expectations and wishes about the Association's activity, the questionnaire used five open questions, which invited the respondents to be creative and give suggestions:

1. How does the Alumni Association look in 2022 so you are proud to be a part of it?

2. What is your role in the Association in 2022 ?

3. What would motivate you to be active in the "ALUMNI ASE" Association?

4. Which are the benefits you would like to have as a member of the "ALUMNI ASE" Association?

5. What do you want the "ALUMNI ASE" Association to do for you?

The approach aimed to determine the way an Alumni Association should look and work in order to inspire graduates, to promote the sense of belonging to the community and ultimately to motivate them to become pro-active.

In this regard, the Association attempted to account personal contributions and resources that graduates are willing to provide to make the Association's objectives feasible. 


\section{The Analysis of Responses}

\subsection{The Alumni Association in 2022}

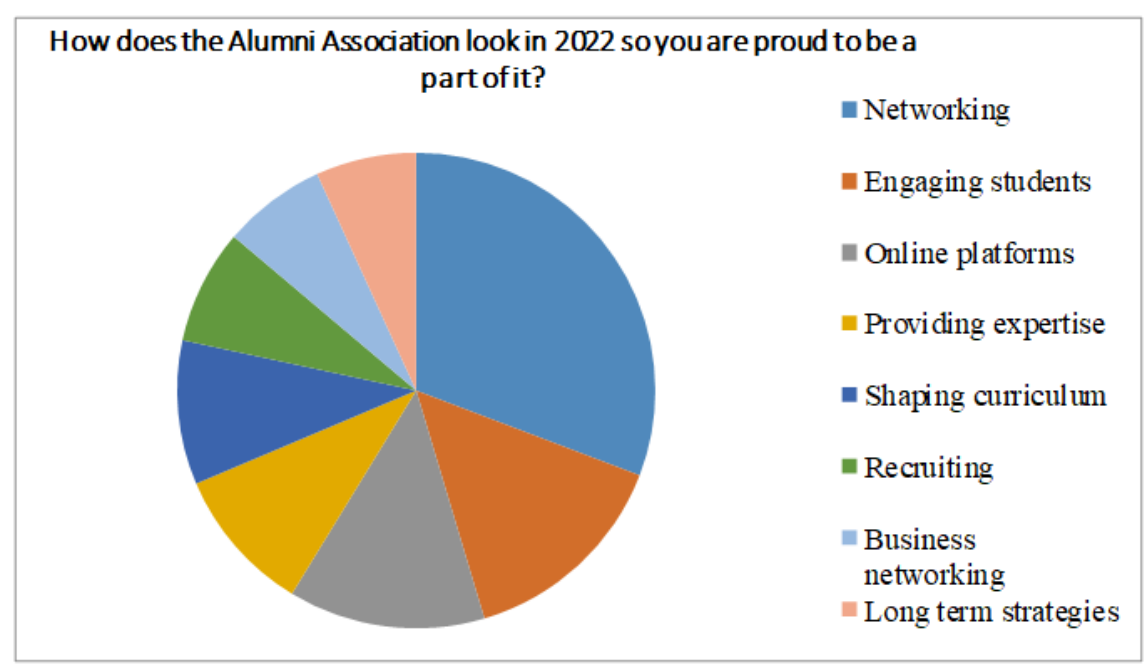

\section{Figure 1. How does the Alumni Association look in 2022 so you are proud to be a part of it?}

To the first question, the answers of the graduates were comprehensive, indicating complex objectives to be achieved in the years through a consolidated strategy.

$\mathbf{3 0 , 8 \%}$ of opinions were that the Association should be a network that allows both the organization of formal events, that harness the experience and expertise of members and non-formal ones, that maintain and strengthen interpersonal relations. In close connection with these events, $\mathbf{1 4 , 6 \%}$ of the graduates have a real interest in interacting with ASE students as mentors, trainers and/or event speakers.

The benefits of mentoring programs are immense for students, alumni and the institution itself. Students have the chance to communicate with professionals who faced in their past the same challenges. They might ask questions and learn about a specific field or company. The mentors provide guidance and advice, as well as professional contacts. Such initiatives give alumni an opportunity to connect with the university and also to train and recruit young people for their workplaces. The institution benefits from mentoring programs as they are tools to strengthen ties to alumni. (Pfeifer, 2002)

Graduates find the Association as an opportunity to get in contact with former colleagues, new business partners or potential collaborators. $13,3 \%$ of the responses indicate that the alumni want to meet their former colleagues and have access to a database with information about them. $\mathbf{7 \%}$ of the opinions were that the Association could become a business hub. This might be the perfect opportunity to identify a new business to start, to learn from other entrepreneurs, find partners and resources. Not only is the relationship with other alumni important, but also with students. $\mathbf{7 , 8 \%}$ of graduates are interested in recruiting students and consider that this process could turn into a profitable situation for both sides.

Another important component is the development of the Association as an advisory or even decisionmaking factor in the economic sector. Analysing $\mathbf{9 , 9 \%}$ of the responses, graduates express their will for the Association to turn into an important think-tank in the development of economic and fiscal policies, with real positive impact on the business market and entrepreneurs. In close link, $\mathbf{9 , 8 \%}$ of respondents consider research as a priority, so the Association could ensure the contact between the university and the business environment, experiencing the challenges of market in real time.

$\mathbf{6 , 8 \%}$ of the answers are in strong connection with the idea of an Association focused on defining a strong strategy, clear goals and accurate planning in the long run.

\subsection{The perception of the future role in the Association}

Alumni's responses were comparable for this question. The responses allow us to delimit the respondents in two categories. The first group express their will to be actively involved in outlining long-term strategies and organizing events $(\mathbf{7 0 , 7 \%})$, while the other group would like to become members and to participate in events created especially for them. 


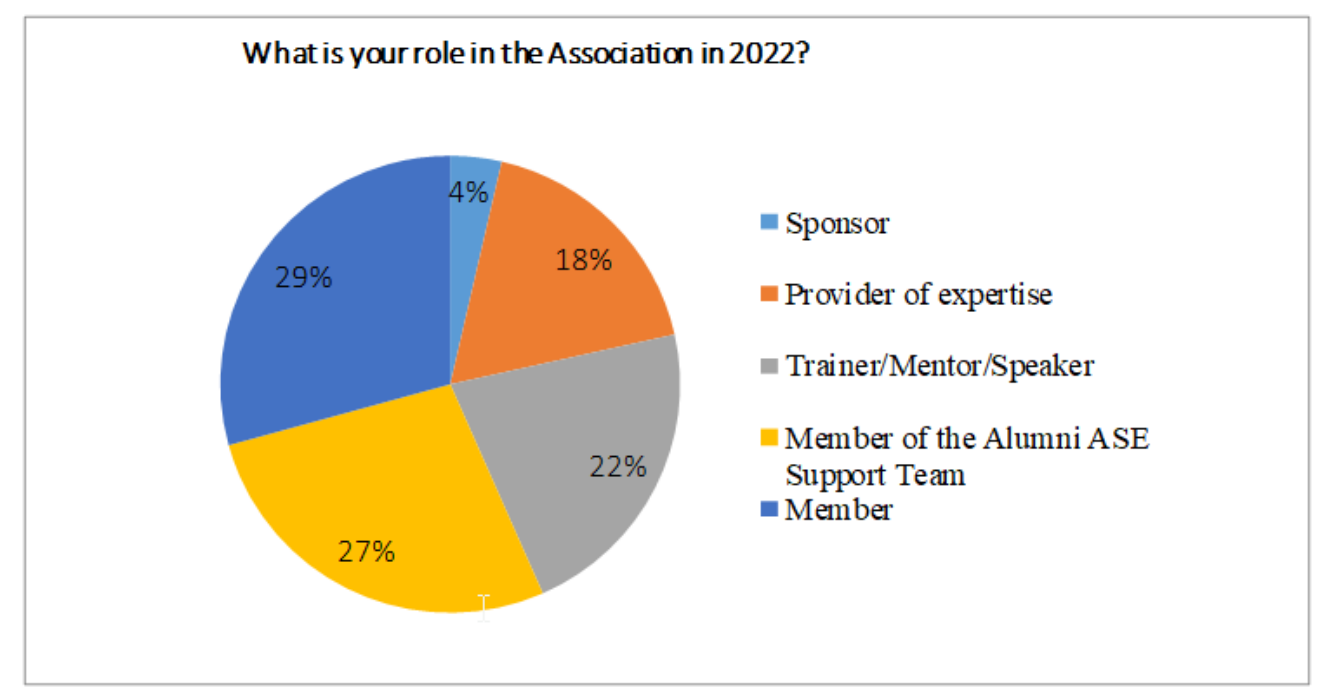

Figure 2. What is your role in the Association in 2022?

Furthermore, the research pursued in finding out which tasks the active group would like to have. $\mathbf{2 7 , 3 \%}$ of them would appreciate being part of the planning and organization team of "ALUMNI ASE" events. The conducted research highlighted the priority to connect with the actual students. Organising events for the students in which keynote speakers are relevant alumni could represent a chance for shaping their career and expectancies, developing new soft skills or even a new mind-set fostering entrepreneurship. $\mathbf{2 1 , 9 \%}$ of graduates want to become mentors / trainers / speakers / facilitators and $\mathbf{1 7 . 9 \%}$ of them are willing to support the Association's work by transferring expertise needed to carry out key projects.

The transition from student to graduate and other relevant aspects from students' life should represent another concern for the Alumni Association. In order to create a group of involved, interested and generous alumni, it is necessary in advance for students who are satisfied with the quality of their studies and the opportunities they have access to. (Andrews, 2012)

Career guidance programs, mentoring and access to information are essential for developing a sense of belonging to the group from an early stage. The relationship between students and graduates must be continuous and consistent.

In addition, $\mathbf{3 , 6 \%}$ of graduates are willing to support the initiatives that fit their personal goals or the companies they represent or run.

Social media might prove to be a very useful tool for attracting funds. Instead of generic e-mails addressed to a database that the Association has built, social networks allow direct and efficient communication with the graduates.

\subsection{The motivation to be active in the Association}

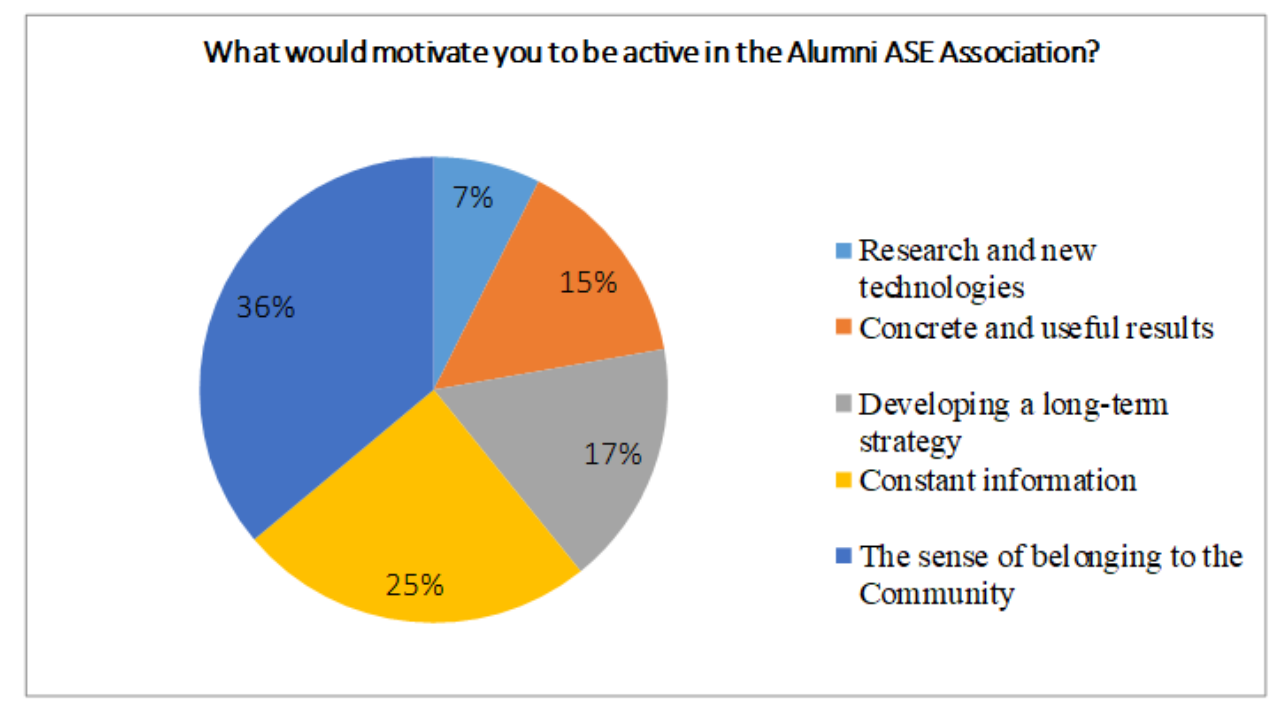

Figure 3. What would motivate you to be active in the "ALUMNI ASE" Association? 
The sense of belonging to the community and the closeness to Alma Mater are some key factors that determine motivation to be actively involved in Alumni Association's projects.

$\mathbf{3 6 , 1 \%}$ of graduates suggest that the strongest motivational factor is simply the idea of being part of this network. Synergy between members and visible outcomes of their engagement increase their motivation. $\mathbf{7 \%}$ of alumni would like to have a deeper understanding of Association's activity, accompanied by information regarding the Board. Transparency it is an important pillar for graduates' motivation.

The communication with Alumni is an essential aspect of Association's management. They have to be informed about current activities, future plans and accomplishments of other graduates or even students.

On demand, those interested about the subject can be updated with information about current research topics, ways of contribution and collaboration with teachers.

A strong long-term strategy would increase the motivation of $\mathbf{1 7 \%}$ of respondents. Linking the strategy with concrete results, which have a quantifiable effect in the society would motivate another $\mathbf{1 4 , 8 \%}$ of graduates. Setting realistic objectives, sustained by activities which produce noticeable effects on short, medium and especially long term is relevant for active participation of the alumni.

There are $\mathbf{8 \%}$ of respondents who would feel motivated if the Association's efforts would focus on developing economic and financial education programmes. The graduates stress the need of creating a body of experts that might represent a strong think-tank capable of having a strong impact in the socio-economic environment.

\subsection{Benefits for graduates}

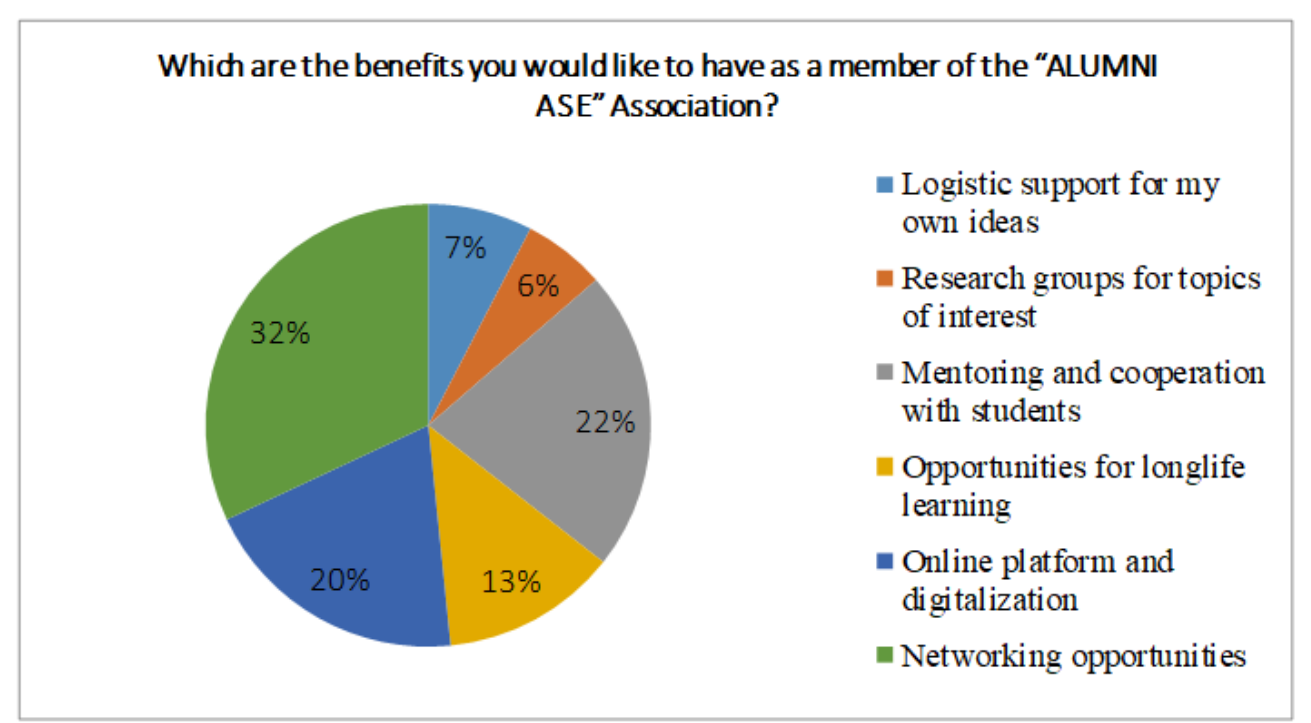

Figure 4. Which are the benefits you would like to have as a member of the "ALUMNI ASE" Association?

The benefits awaited by the graduates can be classified into three main categories: (i) opportunities for communication with former colleagues and potential partners, (ii) access to educational resources and (iii) opportunities to play an active role as speakers in various events, sharing valuable inputs for a successful career.

$\mathbf{3 2 \%}$ of graduates would like to have more networking opportunities, materialized in meetings with former colleagues or other graduates with common interests, business meetings (e.g. conferences, debates, seminars) or informal ones (e.g. reunions, cocktails, gala events). A possible successful event may represent a meeting between young entrepreneurs and investors / business angels / consultants for pitching their business ideas and shaping them accordingly. In addition to the above mentioned events and in link with the aspiration already expressed by previous answers to participate and contribute to students' life, $22 \%$ of respondents seek the opportunity to be facilitators, mentors and trainers. Relevant synergies and outcomes could be obtained within a cooperation between the alumni association and student entrepreneurship clubs / societies.

$\mathbf{1 2 , 8 \%}$ of graduates expect to receive educational resources, discounts on journals' subscriptions, access to publications' databases, tax exemption from participation in some national and international scientific conferences, training courses or seminars and easier access for postgraduate courses or MBA programs offered by the Bucharest University of Economic Studies. Moreover, $\mathbf{6 \%}$ of the alumni would like to join research teams within the university.

One of the most significant benefits for $\mathbf{7 , 6 \%}$ of the graduates might be the Association's openness to their ideas of projects, programmes and events but also the logistical support for implementing them. 
In link with technological progress, $\mathbf{1 9 , 6 \%}$ of respondents believe that another benefit is digitizing the Association's activity and creating an online platform which meets their main needs of networking, information and promotion.

In general, universities are using social media to ease the transition from student to graduate, and to allow the interaction between these two groups. While some universities (e.g. Stanford University) are creating their own platform (with similarities to Facebook), others (e.g. M.I.T., Caltech University, Oregon State University) are making good use of LinkedIn groups that they allow students to access in order to facilitate communication. (Lavrusik, 2009)

\subsection{What do you want the "ALUMNI ASE" Association to do for you?}

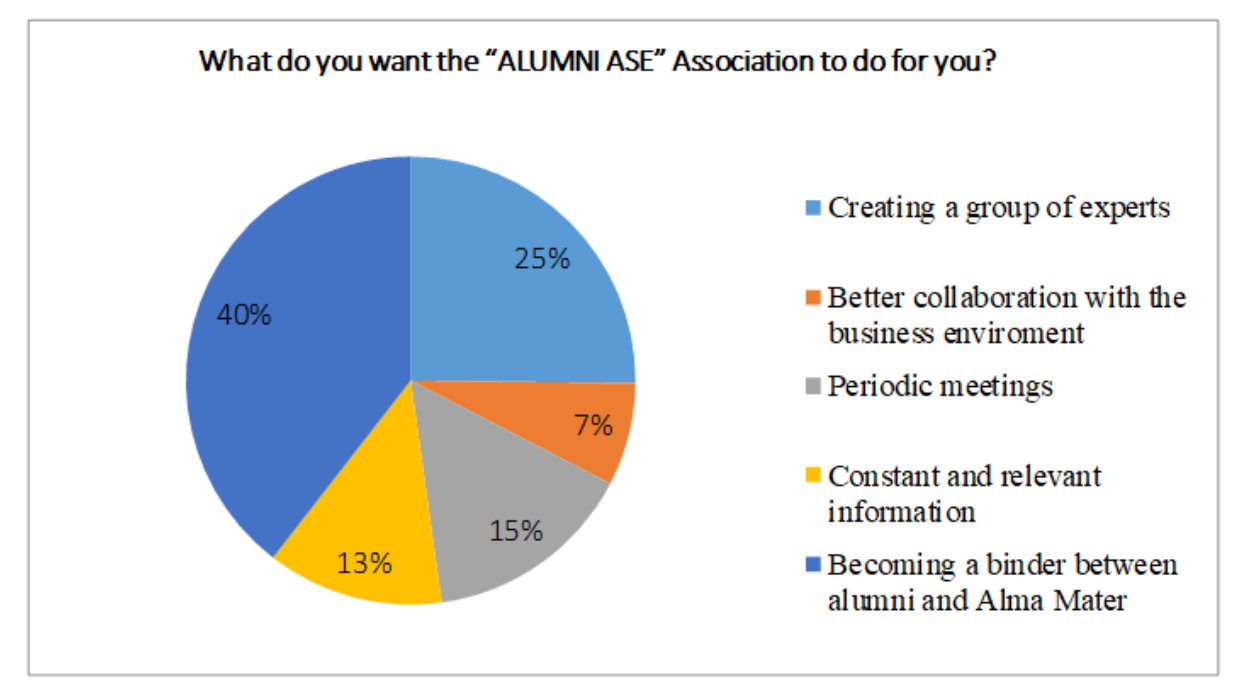

Figure 5. What do you want the "ALUMNI ASE" Association to do for you?

Answering the last question, the graduates were free to formulate requirements, to draw future perspectives and to put forward their view on the Association's development. 39,5\% of them believe that the Association should work as a binder between former colleagues, but also between graduates and students.

Part of the alumni perceive the Association as a source of opportunities.

$\mathbf{2 5 , 2 \%}$ of respondents believe that the Association could become a valuable resource for the academia, an opportunity for lifelong learning and career development for members. Also, in the same category, 7,4\% consider it a priority to develop new entrepreneurship initiatives, facilitate business collaboration and to recruit students for the companies in which the graduates work or they run.

Although some universities create their own recruitment platforms and databases, many of them are using LinkedIn and the benefits of this network. In the most cases, universities just create a group and allow graduates to connect with each other, to create subgroups specialized in regions, fields or industries of interest. Businesses contact universities to distribute career opportunities and they transmit information through various networks to students and graduates. (Lavrusik, 2009)

Likewise, there is a category of graduates interested in closely following the Association. Thus, $\mathbf{1 5 , 2 \%}$ of alumni would like to give feedback on the evolution of the Association and $\mathbf{1 2 , 7 \%}$ of the respondents would contribute in a timely manner to the implement the strategy.

The external communication is another important component. A consistent participation of the graduates in the Alumni Association is enhanced by the way the university depicts its relationship with the graduates and encourages the projects initiated by them.

\section{Conclusions}

Most of the suggestions describe an association with a wide range of activities, both in terms of quantity and quality. It should work as a network that encourages communication and capitalizes members' initiatives.

Graduates have suggested more effective, more creative and slightly more informal communication models that allow a closer connection with members and facilitate their involvement in the projects. Among the most desirable suggestions is the creation of a monthly newsletter that keeps members informed of the association's plans and achievements.

Transparency represents another top priority. Graduates would like to be proper informed about the goals and strategies of the Association.

The idea of creating an online networking space sounds being very attractive for the graduates. In this respect, the Association should be compliant with the Regulation (EU) 679/2016, known as the General 
Regulation on Personal Data Protection (GDPR). Among the aims of this type of platform might be: facilitating access to graduates' contacts (e.g. e-mail, telephone number) and information on their career path; improving the relationship with business environment with the help of graduates in key positions; attracting opportunities for students (e.g. internship and job offers, conferences, soft skills development seminars, career events, company presentations / opportunities). The platform could be complemented by a membership card and bonus system for the most active members.

To create, train and consolidate the expert group, the Association could initiate debates and conferences on current topics of interest (entrepreneurship, banking, marketing, programming, labour market, volunteering, new technologies etc.).

Strengthening the link with the business environment is of great importance. It can be achieved through networking events, job fairs and career opportunities promoted by the alumni to students and also through a start-up incubator.

Alumni would like to reach not only to students but also to high school pupils - future students. By properly promoting study programs and their relevance to the labour market, excellence in higher education in Romania can be brought to the attention of the students.

Graduates express their will to enjoy informal and varied events. Recognizing their professional achievements and initiatives through an Alumni Gala or organizing an annual Alumni Ball are valuable tools in the process of community building.

The current weaknesses are the lack of public exposure and the lack of a suitable marketing strategy for the Association and its future projects. Effective communication represents an issue that maintains and strengthens the sense of belonging to the community as well as motivation. In my opinion, a greater online presence via multi-channels (e.g. Facebook, LinkedIn, Instagram, YouTube) is mandatory but it should focus on sharing content of interest to graduates and to the entire community.

In order to draft a strategy and to develop relevant campaigns, the Association requires well trained human resources. A good solution for bringing the alumni closer to the university is by "Alumni Talks" projects, weekly live show where successful graduates should be invited to participate as guests and to share ideas and advice about their career paths.

The "ALUMNI ASE" Association has all the premises for becoming a think-tank in the economicfinancial sector, a space of interaction between stakeholders, a successful mix of qualitative human capital and material resources.

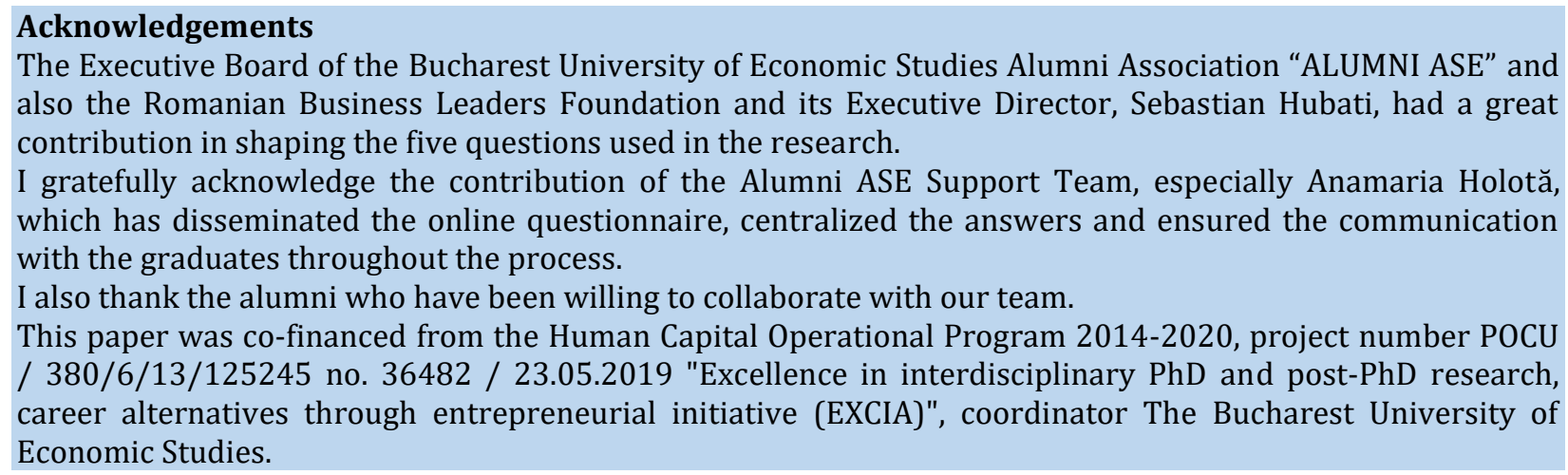

\section{References}

1. Alumni Channel Blog. (2008). "How to start/create an Alumni Association".

(http://alumnichannel.com/blog/how-to-create-an-alumni-association/)

2. Andrews, Margaret. (2012). How do you develop a wildly successful Alumni Relations Effort?, Inside Higher Ed.

(https://www.insidehighered.com/blogs/stratedgy/how-do-you-develop-wildly-successful-alumni-relations-effort)

3. Dolbert, Susan Clouse. (2002). Future Trends in Alumni Relations, Arizona State University Alumni Association. (http://aiec.idp.com/uploads/pdf/ClouseDolbert_pp.pdf)

4. Johnson, Janis. (2015). "Trends and best Practices in Alumni Associations", The Napa Group Publication. (https://napagroup.com/2015/01/31/trends-and-best-practices-in-alumni-associations/)

5. Lavrusik, Vadim. (2009). "10 Ways Universities Are Engaging Alumni Using Social Media". (https://mashable.com/2009/07/23/alumni-social-media/?europe=true)

6. Pfeifer Sarah Elizabeth. (2002). The Benefits of Establishing a Student/Alumni Mentoring Program. The Mentor: An Academic Advising Journal, 4(4) 